\title{
HUBUNGAN ADIKSI GAME ONLINE DAN MEROKOK DENGAN STRES PADA REMAJA
}

\section{RELATIONSHIPS OF ONLINE GAMES AND SMOKING ADDICTIONS WITH STRESS IN ADOLESCENTS}

\author{
Bima Tirta Pradana Ajie Gewab, Erika Diana Risanti, Erna Herawati, Nur Mahmudah \\ Fakultas Kedokteran, Universitas Muhammadiyah Surakarta \\ Korespondensi: dr. Nur Mahmudah, M. Sc. Alamat Email: nm189@ums.ac.id
}

\begin{abstract}
ABSTRAK
Remaja merupakan individu labil yang mudah stres akibat modernisasi. Pemilihan manajemen stres pada remaja yang tidak efektif seperti merokok dan bermain game online menimbulkan adaptasi tubuh yang buruk sehingga berakhir dengan maladaptif atau kegagalan adaptasi masalah yang dihadapi. Penelitian ini bertujuan untuk untuk menganalisis adiksi game online dan merokok dengan tingkat stres pada remaja. Penelitian ini merupakan observasional analitik dengan menggunakan pendekatan cross sectional. Populasi penelitian adalah semua remaja yang bermain game online di Surakarta, sedangkan sampel penelitian sebanyak 56 remaja. Pengumpulan data penelitian menggunakan kuesioner, sedangkan analisis data menggunakan uji Chi square dan Regresi Logistik. Hasil penelitian menunjukkan terdapat hubungan adiksi game online dengan stres remaja ( $p=$ 0,001; OR= 5,312) dan terdapat hubungan merokok dengan stres remaja $(p=0,000 ;$ OR = 5,455), sedangkan besarnya hubungan adiksi game online dan merokok terhadap tingkat stres sebesar 39,0\%. Kesimpulan penelitian adalah adiksi game online dan merokok termasuk mekanisme pengalihan tingkat stres pada remaja.
\end{abstract}

Kata Kunci: Stres Remaja, Adiksi Game Online, Merokok

\section{ABSTRACT}

Adolescents are labile individuals who are easily stress by modernization. Ineffective adolescent stress management choices, such as smoking and playing online games, caused in poor body adaptation, resulting in maladaptive or failure to adapt the problems. This study aimed to analyze online game addiction and smoking with stress levels in adolescents. This study was an analytic observational study used a cross sectional approach. The population was all adolescents who played online games in Surakarta, while the study sample was 56 adolescents. The research data was collected using a questionnaire, while the data analysis used the Chi square test and Logistic Regression. The results showed that there was a relationship between online game addiction and adolescent stress $(p=0.001 ; O R=5.312)$ and there was a relationship between smoking behavior and teen stress levels ( $p=0.000 ; O R=5.455)$, while the magnitude of the relationship between online game addiction and smoking behavior was stress level of 39.0\%. We concluded that online game addiction and smoking behavior included in the mechanism of transferring stress levels in teenagers.

Keywords: Adolescent Stres, Online Game Addiction, Smoking

How To Cite: Gewab, B., Risanti, E., Herawati, E., \& Mahmudah, N. (2020). HUBUNGAN ADIKSI GAME ONLINE DAN MEROKOK DENGAN STRES PADA REMAJA. Biomedika, 12(2), $117-123$. doi:https://doi.org/10.23917/biomedika.v12i2.10737

DOI: https://doi.org/10.23917/ biomedika.v12i2.10737 


\section{PENDAHULUAN}

Kemajuan teknologi dalam beberapa tahun ini berkembang dengan pesat, terutama perkembangan dunia. Internet yang tidak hanya menjangkau kota besar namun pelosok negeri (Young, 2009). Data Asosiasi Penyelenggara Jasa Internet Indonesia (APJII) salah satunya game online, jumlah pengguna internet di Indonesia tahun 2014 telah mencapai 88,1 juta jiwa dari total 252,5 juta jiwa penduduk Indonesia atau sekitar $34,9 \%$ dari penduduk Indonesia (Kasyfi, 2016). Salah satu perkembangan internet yang belakang marak digemari adalah game online, maraknya game online menyebabkan pemain menjadi kecanduan terhadap permainan tersebut (Utama, 2016). Penelitian yang dilakukan oleh Ellyasari (2010) menyatakan bahwa persentase usia pengunjung game online di Surakarta yang terbanyak usia 1620 tahun sebanyak $65,4 \%$ dan mampu bermain game hingga 10 jam.

Penelitian yang dilakukan oleh Young (2009) menjelaskan motivasi seseorang dalam memilih bermain game online secara lebih lanjut yaitu menghindari situasi yang penuh tekanan (stresor), merasa canggung, terisolasi dan tidak aman secara sosial pada kehidupan nyata, ketidakpuasan terhadap dirinya sendiri, dan rendahnya penilaian serta penghargaan dirinya.

Prevalensi kejadian stres di Indonesia saat ini diperkirakan sekitar 1,33 juta penduduk (Legiran dan Bellinawati, 2015). Data Badan Penelitian dan Perkembangan Kesehatan (2013) menyebutkan di Jawa Tengah diperkirakan sekitar 608.000 orang mengalami gangguan stress. Strategi koping pada emosi, di saat orang yang mengalami stres akan melakukan suatu aktivitas lain tanpa melakukan penyelesaian masalah yang dihadapi, misalnya dengan cara melakukan bermain game dan merokok (Long, 2010).

\section{METODE}

Pada penelitian ini telah mendapatkan Ethical Clearance dari KEPK (Komisi Etik Penilaian Kesehatan) dengan nomor penelitian: No. 2602/B.1/KEPK-FKUMS/XI/2019. Data yang diperoleh telah dilakukan informed concent atau persetujuan dengan responden yang bersifat rahasia. Kualitas atau keandalan pada penelitian ini dilakukan dengan mengisi kuesioner yaitu kuesioner Internet Addiction Test (IAT), kuesioner Perilaku Merokok, dan kuesioner Depression, Anxiety, Stres Scale (DASS).

Penelitian ini menggunakan desain penelitian analitik observasional (non- 
eksperimental) dengan pendekatan studi crosssectional. Penelitian ini dilakukan di Surakarta pada bulan Desember 2019. Analisis data bivariat menggunakan uji uji Chi square (2X2), dengan ketentuan apabila nilai sig $(p)<0.05$ (Sastroasmoro dan Ismael, 2014). Analisis data multivariat menggunakan uji regresi logistik untuk melihat variabel independen yang paling dominan memengaruhi variabel dependen (Dahlan, 2014).

\section{HASIL DAN PEMBAHASAN}

Jumlah subjek penelitian sebanyak 56 remaja yang telah memenuhi kriteria retriksi. Variabel bebas yang diukur dalam penelitian yaitu adiksi game online dan perilaku merokok remaja, serta variabel terikat tingkat stres. Karakteristik subjek penelitian ditunjukkan pada tabel 1.

Tabel 1. Karakteristik Subjek Penelitian

\begin{tabular}{cc}
\hline Karakteristik Subjek & Jumlah \\
\hline Usia & \\
16 tahun & 12 \\
17 tahun & 27 \\
18 tahun & 16 \\
19 tahun & 1 \\
Jenis Kelamin & \\
Perempuan & 0 \\
Laki-laki & 56 \\
Tempat Tinggal & \\
Orang tua & 41 \\
Paman/bibi & 14 \\
Kakek/nenek & 1 \\
Status Pernikahan & \\
Orang Tua & \\
Masih bersama & 41 \\
Bercerai & 15 \\
\hline
\end{tabular}

Berdasarkan karakteristik usia responden menunjukkan distribusi tertinggi adalah 17 tahun sedangkan distribusi terendah adalah 19 tahun, dan seluruhnya adalah laki-laki. Sebagian besar sampel tinggal bersama orang tua dengan orang tua yang memiliki status masih bersama.

Tabel 2. Distribusi Frekuensi Tingkat Stres Berdasarkan Adiksi Game Online

\begin{tabular}{cccc}
\hline $\begin{array}{c}\text { Adiksi Game } \\
\text { Online }\end{array}$ & $\begin{array}{c}\text { Tingkat Stres } \\
\text { Tidak } \\
\text { Stres }\end{array}$ & Stres & $\boldsymbol{p}$ \\
\hline Ringan & 0 & 0 & \\
Sedang & 21 & 4 & 0,001 \\
Berat & 12 & 19 & \\
Total & 33 & 23 & \\
\hline
\end{tabular}

Distribusi frekuensi stres berdasarkan adiksi game online (tabel 2) menunjukkan bahwa remaja yang mengalami adiksi game online berat sebagian besar mengalami stress $(p=0,001)$. Berdasarkan distribusi tersebut menunjukkan adanya kecenderungan peningkatan tingkat stres seiring dengan peningkatan adiksi game online.

Hasil penelitian tersebut sesuai dengan teori bahwa game online akan menimbulkan maladaptif pada seseorang karena ketika bermain game online, otak akan menghasilkan dopamine yang merupakan neurotransmitter dan akan ditangkap oleh reseptor dopamine pada sel saraf lainnya sehingga menimbulkan rasa nyaman pada tubuh. Pada saat seseorang berhenti bermain game online makan seseorang tersebut akan mengurangi produksi dopamine sehingga 
neurotransmitter lain di sirkuit otak akan bereaksi untuk meningkatkan dopamine dengan cara bermain game online lagi. Inilah yang disebut sebagai adiksi (Reza, 2016). Adiksi terhadap suatu aktivitas bertujuan untuk menghilangkan rasa cemas, stres, kemarahan, trauma masa lalu, dan lain sebagainya (Beard, 2011).

Berdasarkan penelitian American Medical Associations (AMA) (2007) tentang Emotional and Behavioral Effects of Video Games and Internet Overuse bahwa terjadi pelepasan zat yang menimbulkan perasaan senang dan nyaman ketika bermain game online. Hal yang sama juga muncul ketika seseorang mengkonsumsi narkoba dan menonton film porno. Psikiater Dewi menyebutkan bahwa kecanduan game online lebih bahaya dari narkoba, narkoba punya batas toleransi, yakni sakau atau kematian. Sedangkan game online menyebabkan kerusakan otak tanpa disadari. Secara psikis, emosional seseorang dengan kecanduan game online juga terganggu. Misalnya tiba-tiba dia mendorong temannya, tiba-tiba memukul dan itu sudah menjadi salah satu bukti kecanduan game online juga berpengaruh terhadap emosi remaja (Meyriana dan Siregar, 2017).
Hawadi (dalam Anita dkk, 2018) mengemukakan pada prinsipnya, game memiliki sifat seduktif, yaitu membuat orang menjadi kecanduan untuk terpaku dengan game selama berjam-jam. Game online menyebabkan remaja terasa tertantang sehingga terus-menerus memainkannya, dan menyebabkan remaja tidak memiliki skala prioritas dalam menjalani aktivitas sehari-hari, rendahnya regulasi emosi terhadap ketertarikannya terhadap game online dan pada saat itulah seseorang kecanduan atau bermain game harus bisa mengatur emosi mereka sendiri. Hal ini membutuhkan regulasi emosi pada pecandu game online tersebut.

Penelitian ini menunjukkan adanya hubungan adiksi game online dengan gangguan tingkat stres remaja. Hasil penelitian ini sesuai dengan penelitian sebelumnya, antara lain penelitian Kartika (2017) menyebutkan bahwa remaja dengan usia (12-17 tahun) yang kecanduan game online berdampak buruk terhadap perilaku negatif di Kabupaten Karo.

Tabel 3. Distribusi Frekuensi Stres Berdasarkan Perilaku merokok

\begin{tabular}{|c|c|c|c|}
\hline \multirow{2}{*}{$\begin{array}{l}\text { Perilaku } \\
\text { merokok }\end{array}$} & \multicolumn{2}{|c|}{ Tingkat stres } & \multirow[b]{2}{*}{$p$} \\
\hline & Tidak stres & Stres & \\
\hline Ringan & 27 & 8 & \multirow{4}{*}{0,000} \\
\hline Sedang & 6 & 15 & \\
\hline Berat & 0 & 0 & \\
\hline Total & 33 & 23 & \\
\hline
\end{tabular}


Distribusi stres berdasarkan perilaku merokok (tabel 3) menunjukkan bahwa tidak ditemukan remaja yang memiliki perilaku merokok kategori berat. Berdasarkan distribusi tersebut menunjukkan adanya kecenderungan kejadian stres seiring dengan peningkatan perilaku merokok remaja dengan nilai signifikansi (sig.) $p=0,000, \quad$ sehingga disimpulkan bahwa perilaku merokok memiliki pengaruh yang signifikan terdapat tingkat stres remaja, yaitu semakin tinggi perilaku merokok maka tingkat stres remaja semakin meningkat.

Adanya hubungan perilaku merokok dengan tingkat stres remaja sebagaimana ditunjukkan dalam teori bahwa penggunaan nikotin berpengaruh pada otak yang kemudian menimbulkan efek psikologis seperti penurunan kemampuan mengenali emosi dan cenderung depresi membuat para pecandu rokok terus merokok agar tetap semangat dan lebih tenang. Selain itu nikotin juga dapat memberikan efek kecanduan pada perokok. Kecanduan inilah yang dapat membuat perokok apabila tidak merokok dalam sehari dapat menimbulkan depresi berkepanjangan bahkan stres (Liem, 2010).

Hubungan adiksi game online dan merokok dengan stres remaja di Surakarta, di analisis secara multivariat dengan uji regresi logistic (tabel 4). Syarat variabel yang dapat digunakan untuk analisi regresi logistik adalah variabel yang memiliki $p<0,25$, yaitu variabel adiksi game online dan perilaku merokok.

Tabel 4. Analisis Multivariat Regresi Logistik

\begin{tabular}{lcccc}
\hline Variabel & $\begin{array}{c}\text { Koefi } \\
\text { sien }\end{array}$ & $\boldsymbol{p}$ & $\begin{array}{c}\text { OR/ } \\
\text { Exp } \\
\text { (B) }\end{array}$ & $\mathbf{R}^{\mathbf{2}}$ \\
\hline Adiksi game & 1,670 & 0,018 & 5,312 & \\
online & 1,697 & 0,012 & 5,455 & \\
Perilaku & - & 0,000 & 1,113 & 0,390 \\
merokok & 7,101 & & & \\
Contant & & & & \\
\hline
\end{tabular}

Sumber: Data primer diolah, Desember, 2019

Berdasarkan variabel adiksi game online dengan $\mathrm{OR}=5,312$ artinya variabel adiksi game online, pada remaja yang memiliki adiksi game online berat memiliki risiko 5,312 kali lebih besar untuk mengalami tingkat stres dibandingkan dengan remaja yang memiliki adiksi game online sedang.

Variabel perilaku merokok dengan dengan $\mathrm{OR}=5,455$ artinya variabel perilaku merokok, pada remaja yang merokok kategori sedang memiliki risiko 5,455 kali lebih besar untuk mengalami stres dibandingkan dengan remaja yang perilaku merokok ringan.

Selanjutnya Nagelkerke R2 uji Regresi Logistik adalah sebesar 0,390. Dengan demikian besarnya kontribusi variabel adiksi game online dan perilaku merokok terhadap tingkat stres remaja adalah sebesar $39.0 \%$, sedangkan sisanya sebesar $61.0 \%$ disebabkan oleh faktor-faktor lain 
di luar model, misalnya faktor sosial ekonomi, pengetahuan, sikap, dukungan keluarga dan lainlain.

Stres dapat berupa respon tubuh yang sifatnya-non spesifik terhadap tuntutan beban atasnya. Dalam perkembangan selanjutnya ternyata dampak stres ini tidak hanya mengenai gangguan fungsional hingga kelainan organ tubuh, tetapi juga berdampak pada bidang kejiwaan (psikologik/psikiatrik) misalnya kecemasan atau depresi. Gangguan pada sistem endokrin (hormonal) pada mereka yang mengalami stres adalah kadar gula yang meninggi, dan bila hal ini berkepanjangan bisa mengakibatkan yang bersangkutan menderita penyakit kencing manis (diabetes mellitus) (Hawari, 2008).

Penelitian ini menunjukkan adanya hubungan perilaku merokok terhadap tingkat stres remaja, di mana peningkatan perilaku merokok meningkatkan tingkat stres pada remaja. Hasil ini sesuai dengan penelitian Febriani (2019) yang menyimpulkan bahwa ada hubungan antara frekuensi merokok dengan tingkat stres pada remaja akhir di Universitas Tribhuwana Tungga dewi Malang. Penelitian lainnya yang dilakukan oleh Kaloka (2018) yang menyimpulkan bahwa terdapat pengaruh antara adiksi video game online dan merokok dengan stres pada mahasiswa dengan tingkat adiksi sedang.

\section{SIMPULAN DAN SARAN}

Penelitian ini menyimpulkan bahwa ada hubungan yang signifikan adiksi game online dengan stres remaja dan merokok dengan tingkat stres remaja. Variabel perilaku merokok remaja memiliki hubungan yang lebih dominan dibandingkan tingkat pendidikan remaja terhadap tingkat stres remaja di Surakarta.

Saran yang disampaikan berdasarkan hasil penelitian ini adalah remaja diharapkan belajar untuk mengendalikan dirinya dalam bermain game online, sehingga dengan menjaga durasi atau frekuensi bermain game online, kesehatan mental remaja dapat terjaga salah satunya adalah menghindari timbulnya stres pada remaja. Saran untuk peneliti selanjutnya dapat meneliti variabel lain yang diduga menjadi faktor yang berhubungan dengan tingkat stres remaja, misalnya status sosial ekonomi, faktor dukungan keluarga dan lain sebagainya.

\section{DAFTAR PUSTAKA}

Anita, N., Veny, E., dan Wan, N.D. 2018. Hubungan Kecanduan Bermain Game online Terhadap Regulasi Emosi Pada Remaja. Jurnal JOM FKp. 5(2). Pp: 555562. 
American Medical Associations (AMA). 2007. Emotional and Behavioral Effects of Video and Internet Overuse. Diakses tanggal 08 November 2019. Pp: 1-10.

Asosiasi Penyelenggara Jasa Internet Indonesia (APJII). 2017. Penetrasi dan perilaku pengguana internet Indonesia Diakses tanggal 08 November 2019 dari http://apjii.or.id/survei/2017.

Badan Penelitian dan Perkembangan Kesehatan. 2013. Riset Kesehatan Dasar (RISKESDAS) 2013, Laporan Nasional 2013. Pp: 1-384. doi: 1 Desember 2013.

Beard, K.W. 2011. Working with adolescents addicted to the Internet, Internet addiction: $A$ handbook and guide to evaluation and treatment. doi: 10.1002/9781118013991.ch10.

Dahlan, M.S. 2014. Besar Sampel dan Cara Pengambilan Sampel dalam Penelitian Kedokteran dan Kesehatan. Jakarta: Salemba Medika.

Ellyasari, R.S. 2010. Dampak Penggunaan Game online di Kalangan Mahasiswa (Studi Grounded di Kalangan Mahasiswa Universitas Sebelas Maret Surakarta). Thesis. Surakarta: Fakultas Ilmu Sosial dan Ilmu Politik Universitas Sebelas Maret.

Febriani, O.A., Farida, H.D.K., Yanti, R. 2019. Hubungan Antara Frekuensi Merokok Dengan Tingkat Stres Pada Remaja Akhir. Jurnal Nursing News. 4(1). Pp: 133-44.

Hawari, D. 2008. Manajemen Stres, Cemas dan Depresi. Jakarta: Fakultas Kedokteran UI.

Kaloka, R.M., 2018. Hubungan Tingkat Adiksi Video Game online Dan Kuantitas Merokok Terhadap Tingkat Stres Mahasiswa Fakultas Komunikasi Dan Informatika Universitas Muhammadiyah Surakarta. Thesis. Surakarta: Medical Faculty of Universitas Muhammadiyah.

Kartika, T., 2017. Dampak Game online Terhadap Perilaku Negatif Remaja Usia 12-17 Tahun Di Desa Jinabung Kecamatan
Kutabuluh Kabupaten Karo. Thesis. Fakultas Ilmu Pendidikan Universitas Negeri Medan. Diakses tanggal 08 November 2019 dari http://digilib.unimed.ac.id/25603/3/3/3.\% 20NIM.\%20113337106.pdf.

Kasyfi, H. 2016. Asosiasi Penyelenggaraan Jasa Internet Indonesia. Diperoleh tanggal 08 November 2019 dari http://apjii.or.id/downfile/file/BULETINA PJIIEDISI05November2016.pdf.

Legiran, Z.M.A. dan Bellinawati, N., 2015. Faktor Risiko Stres dan Perbedaannya pada Mahasiswa Berbagai Angkatan di Fakultas Kedokteran Universitas Muhammadiyah Palembang. Jurnal Kedokteran dan Kesehtan. 2(2). Pp: 197202.

Liem, A. 2010. Pengaruh Nikotin Terhadap Aktivitas Fungsi Otak serta Hubungannya dengan Gangguan Psikologi pada Pencandu Rokok. Buletin Psikologi. 18(2). Pp: 37-50.

Long, D. 2010. Smoking as Coping StrategyRespiratory care. Physiological Research. 99(33). Pp: 50-3.

Meyriana, A., dan Siregar, E. 2017. Bahaya Candu Game online. Diakses Tanggal 08 November 2019, dari http;/http://www.liputan6.com/news/re ad/3201814/bahaya-Candu-GimOnline.

Reza, M., Igan, S.A., Gusti, I.A.T., dan Soetjiningsih, W. 2016. Masalah Adiksi Game online pada Anak, Jurnal Psikologi. 43(4), Pp: 262-65.

Sastroasmoro, S. dan Ismael, S., 2014. DasarDasar Metodelogi Penelitan Klinis. Edisi $5^{\text {th }}$. Jakarta: Sagung Seto.

Utama, J. S. 2016. Psikologi dan Teknologi Informasi. Jakarta: HIMPSI.

Young, K. 2009. Understanding Online Gaming Addiction and Treatment Issues for Adolescents. The American Journal of family Therapy. Pp: 355-72. 